Egyptian

Orthodontic Journal

\title{
COMPARISON OF STUDY MODEL AND DIGITAL PANORAMIC RADIOGRAPH IN ESTIMATING TOOTH SIZE AND ARCH LENGTH IN CHILDREN.
}

\author{
Nadia Mostafa Farrag ${ }^{1}$, Salwa Awad ${ }^{2}$
}

\section{ABSTRACT:}

Background: Mixed dentition space analysis helps to assess the amount of space required for the alignment of unerupted permanent teeth in the dental arch.

Objective: This study was conducted to compare between the use of study model and digital panoramic radiograph with special computer software program in estimating tooth size and arch length in children.

Study design: Study models and digital panoramic radiographs with 1:1 magnification factor of one hundred 8-9years old children (50 6oys and 50girls) were obtained. On the model, the mesiodistal tooth size of lower and upper permanent central and lateral incisors were measured with an accurate sliding digital micrometer caliper. Upper and lower arch lengths were also measured from the mesial surface of the first permanent molar in one side of the arch to the mesial surface of the contra lateral side using 0.25 inch stainless steel wire. These measurements were then compared to that obtained from the digital panoramic radiograph using special soft ware program (AVTOCAD 2010). The sum of the mesiodistal dimensions of the four permanent mandibular incisors recorded from the models were used to predict the combined sizes of the unerupted canines and premolars using Moyers, method (at 95\%

1- Assistant professor of Pediatric Dentistry, Mansoura University

2- Lecturer of Pediatric Dentistry, Mansoura University. 
Egyptian

Orthodontic Journal

level of probability). These predicted measurements of unerupted canines and premolars were compared to that measured from the digital panoramic radiographs using (AVTOCAD 2010) program.

Results: $\mathcal{N}$ o statistical significant difference was observed between study model and digital panoramic radiograph with 1:1 magnification factor in estimating tooth size and arch length in children of the present study.

Conclusion: Using 1:1 magnification digital panoramic radiograph with special software computer program is an applicable, accurate and effective method for estimating tooth size and arch length.

\section{INTRODUCTION}

Management of space problems associated with the transitional stages from primary to permanent dentition is a routine procedure of pediatric dental practice (1) $^{(1)}$

The premature loss of the primary molars that results in mesial positioning of the first permanent

molar is of great concern during the mixed dentition leading to crowding $^{(2,3)}$ caused by tooth size-arch length discrepancy. ${ }^{(4-8)}$ Estimation of the mesiodistal widths of unerupted canines and premolars in the early mixed dentition is one of the factors which cause difficulty in evaluation of orthodontic analysis and diagnosis. ${ }^{(9)}$ Inappropriate and invalid estimation of unerupted canines and premolars in the early mixed dentition could lead to extraction decisions that negatively alter a patient's soft tissue profile. $^{(10)}$

Three main approaches have been used to estimate the mesiodistal crown widths of the permanent canines and premolars in the mixed dentition. ${ }^{(11)}$ Measurements of unerupted teeth on the radiographs had been reported by Nance. ${ }^{(12)}$ Moyers ${ }^{(2)}$ and Tanaka and Johnson ${ }^{(13)}$ used the regression equations that relate the mesiodistal widths of erupted teeth to the mesiodistal widths of unerupted teeth. The third method used a 
combination of measurements from erupted teeth and radiographs of unerupted teeth (Hixon and Oldfather). ${ }^{(14)}$ The $75^{\text {th }}$ percentile level of Moyers prediction tables is the globally used method to estimate the mesiodistal crown width of unerupted teeth. ${ }^{(2)}$ This method is still questionable when applied to a population of different ethnic origin. ${ }^{(6,10)}$ At the same time, Tanaka and Johnston analysis tends to over predicts slightly the width of the unerupted teeth. ${ }^{(15)}$

The most accurate predictions of the mesiodistal widths of the unerupted canines and premolars can be obtained by measurements of the mesiodistal widths of these teeth on radiographs combined with the measurement of mesiodistal widths of the erupted mandibular permanent teeth. ${ }^{(6)}$ However, it requires the use of dental casts and radiographs to complete the analysis. ${ }^{(16)}$ The disadvantages of this technique are that the patient is exposed to more radiation and undistorted radiographs of the canines are difficult to obtain. ${ }^{(15)}$

Recently, 1:1 magnification digital panoramic radiographic imaging with a relatively small radiation doses has made the acquisition of radiographic information much easier and accurate for the clinician. ${ }^{(17-21)}$ Therefore, this study was conducted to compare between the use of study model and 1:1 magnification digital panoramic radiograph in estimating the tooth size and arch length in children. The null-hypothesis tested was that there was no difference in measurements between the two methods.

\section{MATERIALS AND METHODS}

One hundred 8-9 years old children (50 boys and 50girls) were selected from the siblings and relatives of children seeking dental treatment at Pediatric Dental Clinic, Faculty of Dentistry, Mansoura University. All the parents of the children signed a consent form for their voluntary participation in the study. The selection criteria were erupted bilateral permanent central and lateral incisors and first permanent molars and absence of any orthodontic treatment, proximal dental caries or restorations, and tooth anomaly.

For every subject, dental casts of both arches were obtained from irreversible hydrocolloid alginate impression material immediately poured 
Egyptian

Orthodontic Journal

with dental stone to avoid any dimensional changes. Digital panoramic $\mathrm{X}$ - ray films with 1:1 magnification were taken for every child in the same day. On each dental cast, the mesiodistal tooth size of the erupted permanent incisors were recorded with an accurate sliding digital micrometer caliper (Mitutoyo Manufacturing Co Ltd, Kawasaki, Japan) by the two examiners to the nearest $0.1 \mathrm{~mm}$. Mesiodistal width is measured between the two anatomical contact points of each tooth parallel to the occlusal surface (Figure1).

For measurement reliability, teeth were measured independently by the two investigators. The two measurements obtained were compared and if they varied by $0.2 \mathrm{~mm}$ or less, the values were averaged. ${ }^{(6)}$ In case where the measurements varied by more than $0.2 \mathrm{~mm}$, the teeth were remeasured and the nearest three measurements were averaged. ${ }^{(10)}$ The sum of the mesiodistal dimensions of the four permanent mandibular incisors recorded from the model were used to predict the combined sizes of the unerupted canines and premolars using Moyers' method (at 95\% level of probability). ${ }^{(2)}$

Arch lengths of both upper and lower jaws were measured on the model from the mesial surface of the first permanent molar in one side of the arch to the mesial surface in the contra lateral side using 0.25 inch stainless steel wire. ${ }^{(22)}$ Using the ruler of special computer program system (AUTOCAD 2010) with 1:1 magnification digital panoramic radiographic images, all the aforementioned measurements were recorded in addition to the mesiodistal dimensions of the crowns of the unerupted permanent canines, first and second premolars (Figures 2-4). In both methods, values obtained from the right and left sides were averaged so that there would be one value for the maxillary canine and premolars and one value for the mandibular canine and premolars. ${ }^{(10)}$ The means and standard deviations (SD) of the teeth widths and arch lengths from the study models and digital panoramic radiographs were calculated and compared for both sexes using student's unpaired t-test. Statistical analysis was carried out using SPSS program version 13 with statistical significance at $5 \%$ level.

Volume 37 - June 2010 
Egyptian

Orthodontic Journal



Figure (1): Mesiodistal crown dimension using sliding digital micrometer caliper.

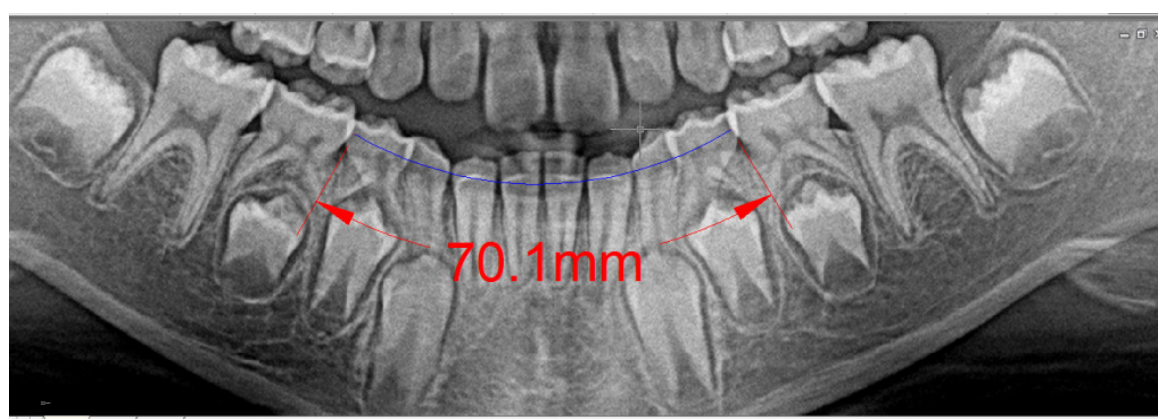

Fig (2): Lower arch length measurement using AUTOCAD 2010 computer program.

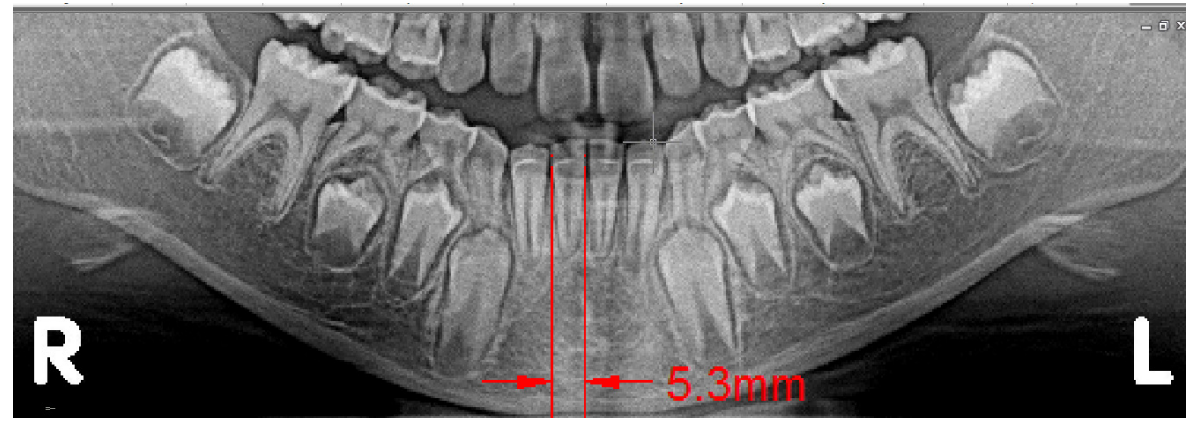

Fig (3): Mesiodistal dimension of lower right central incisor using AOUTOCAD 2010 computer program.

Volume 37 - June 2010 


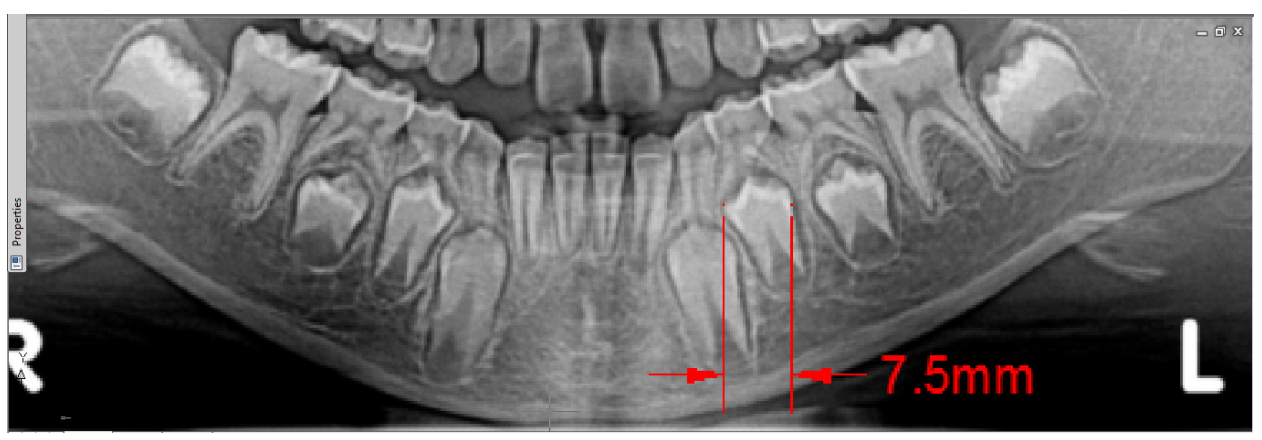

Fig (4): Mesiodistal dimension of lower left second permanent premolar using AUTOCAD 2010 computer program.

\section{RESULTS}

The means and standard deviations of the mesiodistal widths of the individual measured teeth and arch lengths for both sexes using the two different methods were presented in table (1). Although the measurements for males tend to be higher than females, no statistical significant difference was observed either between males and females subjects, or between the study models and digital panoramic radiographs measurements ( $\mathrm{p}$ value $>0.05$ ).

Comparison of the predicted dimensions of unerupted permanent canines and premolars using Moyers' method at 95\% percentile confidence level and the obtained measurements using computerized digital panoramic radiographs can be seen in table (2). The means, and standard deviations of the measured teeth are presented for the combined sexes, males and females subjects .No statistical significant difference was observed in measurements registered by both methods $P>0.05$. Male subjects showed larger mesiodistal tooth dimension of the canines and premolars than female subjects in upper and lower arches without statistical significant differences. 
Egyptian

Orthodontic Journal

Table (1): Comparison of study model and digital panoramic radiograph in estimating teeth widths and arch lengths in $\mathrm{mm}$.

\begin{tabular}{|c|c|c|c|c|c|}
\hline \multirow{2}{*}{\multicolumn{2}{|c|}{ Type of tooth }} & \multirow{3}{*}{$\begin{array}{c}\begin{array}{c}\text { Model } \\
\text { measurement }\end{array} \\
\text { Mean } \pm \text { SD } \\
5.62 \pm .37\end{array}$} & \multirow{3}{*}{$\begin{array}{c}\begin{array}{c}\text { Radiographic } \\
\text { measurement }\end{array} \\
\text { Mean } \pm \text { SD } \\
5.58 \pm .42\end{array}$} & \multicolumn{2}{|c|}{ Test of significance } \\
\hline & & & & \multirow{2}{*}{$\frac{\text { t- test }}{.35}$} & \multirow{2}{*}{$\frac{\text { P value }}{.7}$} \\
\hline I CI & $\mathrm{M}$ & & & & \\
\hline LCI & $\mathrm{F}$ & $5.41 \pm .37$ & $5.32 \pm .41$ & .81 & .4 \\
\hline \multirow{2}{*}{$\begin{array}{l}\text { Test of } \\
\text { significance }\end{array}$} & t-test & 1.79 & 1.98 & & \\
\hline & $P$ value & 0.08 & 0.07 & & \\
\hline \multirow{2}{*}{ LLI } & $\mathrm{M}$ & $6.13 \pm .37$ & $6.22 \pm .40$ & .82 & .4 \\
\hline & $\mathrm{F}$ & $5.91 \pm .41$ & $5.98 \pm .52$ & .52 & .59 \\
\hline \multirow{2}{*}{$\begin{array}{l}\text { Test of } \\
\text { significance }\end{array}$} & t-test & 1.78 & 1.63 & & \\
\hline & $P$ value & 0.08 & 0.11 & & \\
\hline \multirow{2}{*}{ UCI } & $\mathrm{M}$ & $8.70 \pm .51$ & $8.68 \pm .44$ & .14 & .88 \\
\hline & $\mathrm{F}$ & $8.67 \pm .36$ & $8.66 \pm .38$ & .47 & .6 \\
\hline \multirow{2}{*}{$\begin{array}{l}\text { Test of } \\
\text { significance }\end{array}$} & t-test & 0.215 & 0.308 & & \\
\hline & $P$ value & 0.83 & 0.76 & & \\
\hline \multirow{2}{*}{ ULI } & $\mathrm{M}$ & $7.23 \pm .42$ & $7.25 \pm .39$ & .82 & .6 \\
\hline & $\mathrm{F}$ & $7.00 \pm .35$ & $7.12 \pm .41$ & 1.11 & .27 \\
\hline \multirow{2}{*}{$\begin{array}{l}\text { Test of } \\
\text { significance }\end{array}$} & $\mathrm{t}$-test & 1.88 & 1.027 & & \\
\hline & $\mathrm{P}$ value & 0.068 & 0.311 & & \\
\hline \multirow{2}{*}{ UAL } & M & $70.8 \pm 1.40$ & $70.6 \pm 1.30$ & .52 & .6 \\
\hline & $\mathrm{F}$ & $70.5 \pm .94$ & $70.4 \pm 1.28$ & .28 & .77 \\
\hline \multirow{2}{*}{$\begin{array}{l}\text { Test of } \\
\text { significance }\end{array}$} & t-test & 0.796 & 0.49 & & \\
\hline & $P$ value & 0.43 & 0.627 & & \\
\hline \multirow{2}{*}{ LAL } & $\mathrm{M}$ & $70.6 \pm 1.20$ & $70.4 \pm 1.45$ & .53 & .59 \\
\hline & $\mathrm{F}$ & $70.3 \pm 1.12$ & $70.0 \pm .93$ & 1.03 & .3 \\
\hline \multirow{2}{*}{$\begin{array}{l}\text { Test of } \\
\text { significance }\end{array}$} & t-test & 0.817 & 1.119 & & \\
\hline & $P$ value & 0.419 & 0.27 & & \\
\hline
\end{tabular}

No statistical significant difference $\mathrm{P}>0.05$.
LCI: lower central incisor
LLI: lower lateral incisor
UCI: Upper central incisor
ULI: Upper lateral incisor
LAL: lower arch length
UAL: upper arch length

Volume 37 - June 2010 
Egyptian

Orthodontic Journal

Table (2): The estimated dimensions of unerupted permanent canines and premolars using Moyers' method and digital panoramic radiographs.

\begin{tabular}{|c|c|c|c|c|c|}
\hline \multirow{2}{*}{\multicolumn{2}{|c|}{ Type of tooth }} & \multirow{3}{*}{$\begin{array}{c}\text { Radiographic method } \\
\text { Mean } \pm \text { SD } \\
23.6 \pm 1.98\end{array}$} & \multirow{3}{*}{$\begin{array}{c}\text { Moyer method } \\
\text { Mean } \pm \text { SD } \\
23.5 \pm 1.75\end{array}$} & \multirow{3}{*}{$\begin{array}{c}\text { t-test } \\
.24 \\
\end{array}$} & \multirow{3}{*}{$\begin{array}{l}\mathbf{P} \\
.8 \\
\end{array}$} \\
\hline & & & & & \\
\hline \multirow{2}{*}{$\sum \mathbf{L I}$} & $\mathrm{M}$ & & & & \\
\hline & $\mathrm{F}$ & $22.6 \pm 1.28$ & $22.64 \pm 1.32$ & 0.1 & .9 \\
\hline \multirow{2}{*}{$\begin{array}{l}\text { Test of } \\
\text { significance }\end{array}$} & t-test & 1.897 & 1.755 & & \\
\hline & $P$ value & 0.06 & 0.088 & & \\
\hline \multirow{2}{*}{$\sum_{\mathrm{L3}+4+5}$} & $\mathrm{M}$ & $22.57 \pm 1.85$ & $23.2 \pm 1.97$ & 1.57 & .12 \\
\hline & $\mathrm{F}$ & $21.58 \pm 1.64$ & $22.2 \pm 1.74$ & 2.38 & .2 \\
\hline \multirow{2}{*}{$\begin{array}{l}\text { Test of } \\
\text { significance }\end{array}$} & t-test & 1.791 & 1.701 & & \\
\hline & $P$ value & 0.081 & 0.097 & & \\
\hline \multirow{2}{*}{$\begin{array}{l}\sum_{\mathrm{U} 3+4+5} \\
\end{array}$} & M & $22.53 \pm 1.90$ & $23.1 \pm 1.82$ & 1.54 & .11 \\
\hline & $\mathrm{F}$ & $21.78 \pm 1.54$ & $22.2 \pm 1.64$ & 1.75 & .08 \\
\hline \multirow{2}{*}{$\begin{array}{l}\text { Test of } \\
\text { significance }\end{array}$} & t-test & 1.371 & 1.643 & & \\
\hline & $P$ value & 0.178 & 0.108 & & \\
\hline
\end{tabular}

$\sum$ LI: sum of lower central incisors width.

$\sum$ L 3+4+5:sum of lower permanent canine, first and second premolars width.

$\sum \mathrm{U} 3+4+5$ :sum of upper permanent canine, first and second premolars width.

No statistical significant differences $\mathrm{P}>0.05$

\section{DISCUSSION}

One of the most critical factors in dental arch development and the relation of the arches to one another is mesiodistal tooth size.

The size of the teeth is related to genetics (e.g., gender and ethnicity) and environment. Racial and gender-specific mixed dentition space and analysis requires revision or validation once every generation (approximately 30 years) because of changing trends in malocclusion and tooth size ${ }^{(7,23,24)}$. The accurate width of unerupted tooth is important for correct diagnosis of a case. If predicted values of the width of the canines and premolars itself is wrong, the whole treatment may be a failure. ${ }^{(10)}$ 
Egyptian

Orthodontic Journal

Dental cast is the traditional three dimensions patient record for measuring linear changes in the dental arch. However, model analysis is performed manually with a number of limitations in terms of accuracy and measuring ability. ${ }^{(25)}$ In addition, it is difficult to take impression for young uncooperative child with gagging reflex needing considerable time and energy. To overcome these problems, recent digital radiography and technologic computer program that facilitate measurements can be used.

Digital Panoramic radiography delivers relatively small radiation doses, i.e. effective dose to the patient for single panoramic image is approximately equal to that from four intra oral peri-apical images both using state-of-the-art technique. ${ }^{(17)}$ This new technology eliminates the need for film and film developing technique with the subsequent errors. ${ }^{(26)}$ Moreover, digital imaging systems provide numerous software tools that impact the ability to accurately interpret the radiographic image. ${ }^{(21)}$ A simple mouse click will enable computer-assisted digital tools to record mesiodistal width of the teeth or arch length measurements. Unlike study models, computerized digital images are less likely to be misplaced or broken and present no storage problems. ${ }^{(15)}$ The internet-based data transmission system will facilitate an efficient and convenient exchange of orthodontic data and patients' records. ${ }^{(25)}$ These digital images can be imported to the patient's record as static images for electronic archiving or printing. ${ }^{(15,26)}$

In the present study, the mesiodistal width of the erupted lower and upper incisors, and arch lengths from the model were compared to that calculated by special computer measuring program (AUTOCAD 2010) using 1:1 magnification digital panoramic radiograph. The results showed that the mesiodistal widths of the erupted and unerupted teeth in male subjects were greater than that of females with no statistically significant difference $(\mathrm{p}>0.05)$ as shown in tables $(1,2)$.

The difference in the combined mesiodistal tooth dimension of the canines and premolars between both genders in the maxillary and mandibular arches was also not statistically significant (table 2). Many authors $^{(16,27)}$ found similar results although many others do not differentiate the genders when predicting mesiodistal diameters of these teeth. ${ }^{(2,13,28)}$ 
To utilize the Moyers' probability tables, the sum of mesiodistal width of the lower incisors is measured and the number is used to predict the size of both the lower and upper combined width of the canines and premolars. ${ }^{(2)}$ The mandibular incisors have been chosen for measuring, since they are erupted first in the mouth early in the mixed dentition, are easily measured accurately, and are directly in the midst of most space management problems. ${ }^{(2)}$ The maxillary incisors are not used in any of the predictive procedures since they show too much variability in size, and the correlations with other groups of teeth are of lower predictive value. $^{(10)}$

The accurate width of an unerupted tooth is important for correct diagnosis of a case. Neither overestimation nor underestimation of width should be done for accurate treatment plan. This study revealed that the Moyers charts at the $95^{\text {th }}$ percentile confidence level showed no statistically significant difference compared to that calculated by AUTOCAD 2010 computer program using digital panoramic radiograph with 1:1 magnification factor table $(1,2)$ so, the null-hypothesis testing is accepted.

\section{Conclusion and Recommendation:}

The use of 1:1 magnification digital panoramic radiograph with special computer soft ware program is a simple and relatively accurate method for estimating the mesiodistal widths of teeth and arch length. This proposed method must be tested in other samples and situations to confirm its reliability and consistency.

\section{REFERENCES}

1) Foster TD, Hamilton MC. Occlusion in primary dentitions. Br Dent J, 126:76-79, 1960.

2) Moyer RE. Handbook of Orthodontics. Analysis of the dentition and occlusion. $4^{\text {th }}$ ed. Year book medical publisher, 235-238, 1988. 
3) Johnsen DC. Space observation following loss of the mandibular first primary molars in mixed dentition. J Dent Child, 47:24-27, 1980.

4) Owen DG. The incidence and nature of space closure following the premature extraction of deciduous teeth. A literature survey. J Orthod, 59:37-49, 1971.

5) Foster TD, Grundy MC. Occlusal changes from primary to permanent dentitions. Br J Orthod,13:187-193,1986.

6) Bishara SE, Jakobsen JR, Treder JE, Stasi MJ. Changes in the maxillary and mandibular tooth size-arch length relationship from early adolescence to early adulthood. A longitudinal study.Am J Orthod Dentofacial Orthop, 95:46-59, 1989.

7) Bishara SE, Khadivi P, Jakobsen JR. Changes in tooth size-arch length relationships from the deciduous to the permanent dentition: a longitudinal study. Am J Orthod Dentofacial Orthop,108:607-613,1995.

8) Bishara SE, Treder JE, Damon P, Olsen M. Changes in the dental arches and dentition between 25 and 45 years of age. Angle Orthod, 66:417-422, 1996.

9) Hunter WS. Application of analysis of crowding and spacing of teeth. Dental Clinics of North America, 22:563-577, 1978.

10) Durgekar G S, Naik V. Evaluation of Moyer's mixed dentition analysis in school children. Indian J Dent Res, 20(1):26-30, 2009.

11) Schneider, P.E.: Predicting the mesial-distal dimensions of teeth with panoramic radiography, MS thesis, University of Indiana- School of Dentistry, Indianapolis, 1972 (Microfilm).

12) Nance HN. The limitations of orthodontic treatment: Mixed dentition diagnosis and treatment. American Journal of Orthodontics, 33:177-223, 1947.

13) Tanaka, M.M., and Johnston, L.E.: The Prediction of the size of unerupted canines and premolars in a contemporary orthodontic population. JADA, 88:798-801, 1974. 
14) Hixon EH, Oldfather RE. Estimation of the sizes of unerupted cuspid and bicuspid teeth. Angle Orthod, 28:236-240, 1958.

15) Pinkham J R, Casamassimo P S, McTigue D J, Fields H W Jr, Nowak A J. Pediatric Dentistry Infancy through Adolescence. Examination, Diagnosis and Treatment planning. $4^{\text {th }}$ ed Elsevier Sanders, 2005, p.499.

16) Wangpichit K, Huntington N L, Kapa1. Methods of mixed dentition analysis in cleft lip patients. J Pediatr Dent 23:478-480, 2001.

17) Dove SB, McDavid WD. A comparison of conventional intra-oral radiography and computer imaging techniques for the detection of proximal surface dental caries. Dentomaxillofac Radiol, 21:127-34, 1992

18) Kilic AR, Efeoglu E, Yilmaz S, Orgun T. The relationship between probing bone loss and Standardized radiographic analysis. Periodontal Clinical Investigations, 20:25-32, 1998.

19) Gibbs SJ. Effective dose equivalent and effective dose: comparison for common projections in oral and maxillofacial radiology. Oral Sur Oral Med Oral Pathol Oral Radiol Endod, 90: 538-45, 2000.

20) Schulze R, Krummenauer F, Schalldach F, d'Hoedt B. Precision and accuracy of measurements in digital panoramic radiograph. Dentomaxillofacial Radiology, 29(1):52-56, 2000.

21) White SC, Pharoah MJ. Oral radiology: principles and interpretation $5^{\text {th }}$ ed. St. Louis: Mosby; 2004.

22) Hong Q ,Shrestha S, Nakano K. Study and comparison of tooth size and arch length in Angle class $\amalg$ malocclusion between Nepalese and Chinese population. J of hard tissue Biology, 17(2): 69-76, 2008.

23) Howe RP, McNaramara JA Jr, O' Connor KA. An examination of dental crowding and its relationship to tooth size and arch dimension. Am J Orthod, 83:363-373, 1983.

24) Warren JJ, Bishara SE. Comparison of dental arch measurements in the primary dentition between contemporary and historic samples. Am J Orthod Dentofacial Orthop, 119:211-215, 2000. 
25) Cha BK, Lee JY,Jost-Brinkmann PG, Yoshida N. Analysis of tooth movement in extraction casis using three dimensional reverse engineering technology. Europ J of Ortho, 29(4): 325-331, 2007.

26) Khocht A ,Janal M,Chang K. Comparison of direct digital and conventional intra oral radiographs in detecting alveolar bone loss. JADA, 134:1468-1475, 2003.

27) Schirmer UR,Wiltshire WA. Orthodontic probability tables for black patients of African descent: Mixed dentition analysis. Am J Orthod Dentofacial Orthop, 112:545-551, 1997.

28) Motokawa W, Ozaki M, Soejima Y. A method of mixed dentition analysis in the mandible. J Dent Child, 54:114-118, 1987. 